\title{
The Effect Of Smoking on the Healing of Extraction Socket - A Retrospective Study
}

\author{
Research Article
}

Pradeep D ${ }^{1}$, Meghana Reddy J J $^{*}$ Deepika Rajendran ${ }^{3}$

${ }^{1}$ Associate Professor, Department of Oral and Maxillofacial Surgery, Saveetha Dental College and Hospitals, Saveetha Institute of Medical and Technical Sciences, Saveetha University, Chennai, India.

${ }^{2}$ Saveetha Dental College and Hospitals, Saveetha Institute of Medical and Technical Sciences, Saveetha University, Chennai, 600077, India.

${ }^{3}$ Senior lecturer, Department of Oral Medicine and Radiology, Saveetha Dental College and Hospitals, Saveetha Institute of Medical and Technical Sciences, Saveetha University, Chennai, India.

\section{Abstract}

Extraction is one of the most common surgical procedures done. Dental extraction is the removal of teeth from the dental socket in the alveolar bone. Extractions are performed to remove teeth which have extensive dental caries, periodontal disease, or dental trauma. Smoking is one of the leading causes of early death worldwide. The various complications of smoking associated with post-operative extraction sites are delayed wound healing, Dry socket and effect on periodontal tissue. The aim of the study is to assess the post operative extraction site in smokers. A University based study was conducted. Inclusion criteria included Extracted tooth or teeth in smokers. Exclusion criteria included Pregnant or nursing women, patients allergic to local anesthetics, antibiotics or analgesics, Patients with cardiovascular disease or any other systemic pathology. Data collection was done by reviewing the patients records and analysing the data of 46 patients between June 2019 and March 2020, then excel tabulation and Statistical analysis was done using SPSS and Pearson chi-square test was performed. Total 46 patients were included in the study out of which 5 were female and 41 were males. In males socket healing was unsatisfactory in 10 patients whereas in females socket healing was unsatisfactory in 2 patients. Within the limits of this study, it is concluded that the Post-operative healing site of smokers was Satisfactory.

Keywords: Extraction; Smoking; Smoker; Socket Healing; Pain; Dry Socket.

\section{Introduction}

Extraction is one of the most common surgical procedures performed in the speciality of Oral and Maxillofacial Surgery $[1,2]$. Dental anxiety is a major predictor of pain experienced by patients during dental extractions. Hence it is important to reduce the anxiety before the treatment to reduce the pain during extraction $[3,4]$. One of the most common causes of maxillofacial trauma is road traffic accidents, in which extraction of teeth in fracture line is removed [5]. In some cases of inferior alveolar nerve block for removal of mandibular molar, facial paralysis can occur .Botulinum toxin can be used for management of facial paralysis and various traumatic injuries of the face [6].

Dental extraction is the removal of teeth from the dental socket in the alveolar bone. Extractions are performed to remove teeth which have extensive dental caries, periodontal disease, or dental trauma, especially when they are associated with severe toothache. Sometimes when the impacted teeth cause infection, swelling and pain it can be extracted. Impacted third molars are removed before doing mandibular and maxillary osteotomies [7, 8]. The pain experienced after the dental extraction is likely to be one of the most severe pain. Ketorolac reduces the intensity of pain and lasts longer when compared to paracetamol [9]. Dental professionals are at a greater risk for acquiring cross infections while treating patients. The waste produced in the course of healthcare activities has a higher potential for infection and injury. Therefore biomedical waste should be handled in an appropriate way [10].

According to the World Health Organization (WHO), smoking is one of the leading causes of early death worldwide. Smoking negatively impacts the oral health of an individual. Usage of tobac-

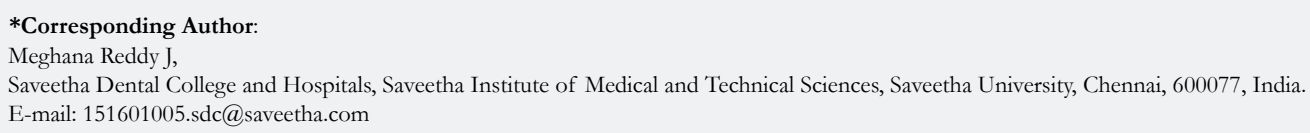

Copyright: Meghana Reddy $\mathbf{J}^{\odot}$ 2019. This is an open-access article distributed under the terms of the Creative Commons Attribution License, which permits unrestricted use, distribution and reproduction in any medium, provided the original author and source are credited. 
co affects oral tissues causing various pre-cancerous lesions and carcinomas of the mouth and pharynx [11]. Oral squamous cell carcinoma is one of the most commonly occurring oral lesion, in which extraction of hopeless teeth is done before radiotherapy. In some salivary gland pathology, like ranula, mucocele occur due to sharp teeth, that can be either conservatively managed or extracted. While giving local anesthesia during extraction, care to be taken to prevent needle stick injuries [12-14]. Maxillary impacted third molar is removed before or during maxillary osteotomies to prevent post operative infection [15].

The various complications of smoking associated with post-operative extraction site are delayed wound healing and dry socket. Many Studies have shown that smoking delays wound healing and affects bone remodelling. Tobacco is a peripheral vasoconstrictor, along with its products like nicotine it increases platelet adhesiveness, raises the risk of microvascular occlusion, and causes tissue ischemia [16]. Tobacco smoking is also associated with catecholamines release resulting in vasoconstriction and decreased tissue perfusion. Smoking is believed to suppress the innate and host immune responses, affecting the function of neutrophils which is the prime line of defence against infection. Thus, it shows the relation between smoking and delayed wound healing $[17,18]$.

Dry socket generally occurs due to the heat from the cigarette smoking and tobacco along with its by-products could act as a contaminant in the surgical site which might dislodge the clot from the alveolus interrupting healing of the socket [19-21]. Smoking is reported to be an important factor responsible for postoperative infections which can lead to failure of surgery. It may be an important factor predisposing to wound dehiscence or flap laceration following surgeries [22, 23]. Smoking tobacco can cause periodontal destruction whereas smokeless tobacco causes gingival recession at the site of placement.

Postoperative complications were low when eugenol based paste was applied on the molar extraction site for 7 days [24]. In cases of Oral submucous fibrosis, restricted mouth opening causes difficulty in extraction. After a traumatic extraction or due to to- bacco usage if the post-operative site does not heal properly and if there is oro antral communication then graft can be provided to give better results [25]. Dental extraction can cause bacteremia and a small number of patients can contract infective endocarditis. Antibiotic prophylaxis can be given to avoid this complication [26].

This research is important for the success of post-operative healing in smokers, to avoid dry socket formation, pain and swelling. To reduce the post-operative infection and to generate bone formation [27]. The aim of the study was to assess post operative extraction sites in smokers.

\section{Materials And Methods}

A University based study was conducted where two people were involved (1 guide and 1 Student). All the teeth indicated for extraction in smokers were taken into consideration. The data retrieval is easier because of similar ethnicity and specific time period. Inclusion criteria included Extracted tooth or teeth in smokers. Exclusion criteria included Pregnant or nursing women, patients allergic to local anesthetics, antibiotics or analgesics, Patients with cardiovascular disease or any other systemic pathology.

The study was conducted with the approval of the Institutional Ethics Committee [SDC/SIHEC/2020/DIASDATA/0619-0320]. Data collection was done by reviewing the patients records and analysing the data of 46 patients between June 2019 to March 2020, excel tabulation, Statistical analysis was done using SPSS and Pearson chi-square test was performed. Statistical analysis was done by exporting the data to SPSS for data checking. Data was sorted and then represented in frequencies. Calculating frequencies and sorting. Descriptive results were presented using mean, tables and graphs.

\section{Results And Discussion}

Out of total 46 patients $5(10.87 \%)$ were female and $41(89.13 \%)$ were males. The mean age was 45 years. The age ranged from 20

Graph 1. This graph shows association between gender of participants and post-operative healing (satisfactory and unsatisfactory) site in smokers where blue colour denotes Satisfactory healing with $6.52 \%$ in females and $67.39 \%$ in males, red colour denotes unsatisfactory healing with $4.35 \%$ in males and $21.74 \%$ in females. Healing was unsatisfactory in females when compared with males. The $\mathrm{X}$ axis shows the gender of the participants and the $\mathrm{Y}$ axis shows the Post operative healing site (satisfactory and unsatisfactory) in smokers. Pearson chi-square test was done for gender of participants and post operative healing site, $P=0.920$ ( $>0.05$ - indicating statistically not significant).

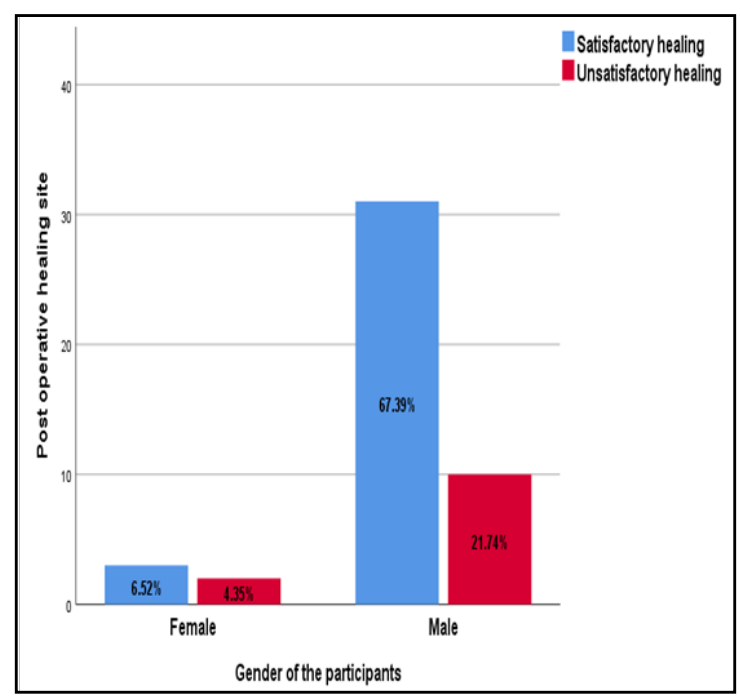


Graph 2. This graph shows association between the age of participants and post-operative healing site in smokers where blue colour indicates satisfactory healing and red colour indicates Unsatisfactory healing. Satisfactory healing was better in the age group of $41-50$ years with $26.1 \%$. The $X$ axis represents the age of the participants and the $\mathrm{Y}$ axis represents the post operative healing site (satisfactory and unsatisfactory healing). Pearson chi-square test was done, $P=0.007$ for age of the participants and post operative healing ( $>0.05$ - indicating statistically not significant).

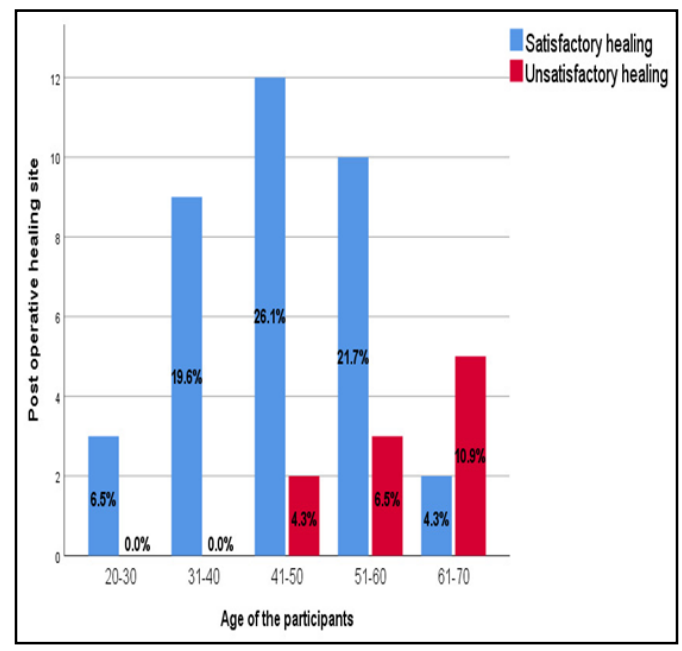

to 70 years.

In males $21.74 \%$ (10 patients) socket healing was unsatisfactory whereas in females $4.35 \%$ (2 patients) socket healing was unsatisfactory as seen in the (Graph 1).

Post-operative socket healing was better in 41-50 (26.1\%) year old patients when compared to $61-70(4.3 \%)$ year old patients who had the least socket healing capacity was seen in (Graph 2).

Cigarette smoking affects the oral cavity in various ways ranging from staining of the teeth to oral cancers. Most of the studies on postoperative complications from extractions were on mandibular third molars, particularly those with impactions. This study is based on a wide range of extractions performed in Saveetha Dental College. Incidence of gender and post-operative healing site was assessed. The post-operative healing rate was unsatisfactory in males when compared with females. Larrazabal, Carolina, et al. in his study collected data on postoperative smoking showed that the majority of patients who smoked continued to do so postoperatively [28]. Studies that showed the similar results are - Al-Belasy, Fouad A et al., and contradicting results were seen in Carriches, Carmen López, et al., where the post operative healing site was unsatisfactory in female patients when compared to male patients. Overall consensus - Disagree because the sample size was very limited for female patients and the post operative healing results changed $[29,30]$.

Age and Post-operative healing site was assessed. Studies that showed similar findings are Zajak J., et al., where the healing site was unsatisfactory as age increased. Overall consensus - Agree the age groups were similar and post operative healing was satisfactory and as the age increased the healing was unsatisfactory.

The difficulties faced by other researchers are:

1. The article aims at reviewing the effects of tobacco upon the healing capacity of oral tissues following routine surgical procedures performed in the oral cavity. Balaji S . M et al., [31].

2. This study clarified the relationship between smoking and postoperative complications. Although smoking was found to be associated with increased postoperative complications for all extractions combined, the relationship was altered when distinctions were made among different types of extractions.. Heng, Christine k, et al, 2007 [32].

3. Cigarette smoking does not seem to have any statistically significant relationship on the severity of pain, swelling and trismus after surgical removal of lower third molar on males and larger sample sizes from both gender and other types of tobacco smoking, such as cigar need to be conducted. Ra'ed, M et al., 2013 [33].

\section{Acknowledgement and Declarations}

The study was supported by Saveetha Dental College \& Hospitals, Saveetha Institute of Medical and Technical Sciences, Saveetha University, Chennai.

\section{Conclusion}

With the limits of this study, it was concluded that the Postoperative healing site of smokers was Satisfactory. The Sample size should have been larger, Precautions can be taken for better healing and Better instructions and treatment should be given for patients with low healing capacity. The components of cigarette smoke clearly have an inhibitory effect on wound healing. Combined effects of nicotine, carbon monoxide and hydrogen cyanide are tissue ischemia, cellular hypoxia, inhibition of proliferation of epithelial cells, vasoconstriction, and a decrease in oxygen carrying capacity of blood cells required for wound healing. All clinicians should take these complicating factors into account and advise the patient to quit the habit and inform them about the prognosis of treatment.

\section{References}

[1]. Venkateshwar GP, Padhye MN, Khosla AR, Kakkar ST. Complications of exodontia: a retrospective study. Indian J Dent Res. 2011 Sep 1;22(5):633-8.

[2]. Patturaja K, Pradeep D. Awareness of Basic Dental Procedure among General Population. Research J Pharm Technol. 2016;9(9):1349-51.

[3]. Kumar S. Relationship between dental anxiety and pain experience during dental extractions. Asian J Pharm Clin Res. 2017;10(3):458-61. 
[4]. Sweta VR, Abhinav RP, Ramesh A. Role of Virtual Reality in Pain Perception of Patients Following the Administration of Local Anesthesia. Ann Maxillofac Surg. 2019 Jan-Jun;9(1):110-113.Pubmed PMID: 31293937.

[5]. Abhinav RP, Selvarasu K, Maheswari GU, Taltia AA. The Patterns and Etiology of Maxillofacial Trauma in South India. Ann Maxillofac Surg. 2019 Jan-Jun;9(1):114-117.Pubmed PMID: 31293938.

[6]. Kumar S. The emerging role of botulinum toxin in the treatment of orofacial disorders: literature update. Asian J Pharm Clin Res. 2017;10(9):21.

[7]. Adeyemo WL, Taiwo OA, Oderinu OH, Adeyemi MF, Ladeinde AL, Ogunlewe MO. Oral health-related quality of life following non-surgical (routine) tooth extraction: A pilot study. Contemp Clin Dent. 2012 Oct;3(4):427-32. Pubmed PMID: 23633803.

[8]. Vijayakumar Jain S, Muthusekhar MR, Baig MF, Senthilnathan P, Loganathan S, Abdul Wahab PU, et al. Evaluation of Three-Dimensional Changes in Pharyngeal Airway Following Isolated Lefort One Osteotomy for the Correction of Vertical Maxillary Excess: A Prospective Study. J Maxillofac Oral Surg. 2019 Mar;18(1):139-146.Pubmed PMID: 30728705.

[9]. Rao TD, Kumar MP. Analgesic Efficacy of Paracetamol Vs Ketorolac after Dental Extractions. Research J. Pharm. and Tech. 2018;11(8):3375-9.

[10]. Kumar S, Rahman RE. Knowledge, awareness, and practices regarding biomedical waste management among undergraduate dental students. Asian J Pharm Clin Res. 2017;10:341.

[11]. Yanagisawa T, Ueno M, Shinada K, Ohara S, Wright FA, Kawaguchi Y. Relationship of smoking and smoking cessation with oral health status in Japanese men. J Periodontal Res. 2010 Apr;45(2):277-83.Pubmed PMID: 19744265.

[12]. Marimuthu M, Andiappan M, Wahab A, Muthusekhar MR, Balakrishnan A, Shanmugam S. Canonical Wnt pathway gene expression and their clinical correlation in oral squamous cell carcinoma. Indian J Dent Res. 2018 May 1;29(3):291-7.

[13]. Packiri S, Gurunathan D, Selvarasu K. Management of Paediatric Oral Ranula: A Systematic Review. J Clin Diagn Res. 2017 Sep;11(9):ZE06-ZE09. Pubmed PMID: 29207849

[14]. RAHMAN R, MP SK. KNOWLEDGE, ATTITUDE, AND AWARENESS OF DENTAL UNDERGRADUATE STUDENTS REGARDING HUMAN IMMUNODEFICIENCY VIRUS/ACQUIRED IMMUNODEFICIENCY SYNDROME PATIENTS. Asian J Pharm Clin Res. 2017;10(5):175-80.

[15]. Christabel A, Anantanarayanan P, Subash P, Soh CL, Ramanathan M, Muthusekhar MR, et al. Comparison of pterygomaxillary dysjunction with tuberosity separation in isolated Le Fort I osteotomies: a prospective, multi-centre, triple-blind, randomized controlled trial. Int J Oral Maxillofac Surg. 2016 Feb;45(2):180-5.Pubmed PMID: 26338075

[16]. Mayfield L, Söderholm G, Hallström H, Kullendorff B, Edwardsson S, Bratthall $\mathrm{G}$, et al. Guided tissue regeneration for the treatment of intraosseous defects using a biabsorbable membrane. A controlled clinical study. J Clin Periodontol. 1998 Jul;25(7):585-95.Pubmed PMID: 9696260.

[17]. Al-Belasy FA. The relationship of "shisha" (water pipe) smoking to postextraction dry socket. J Oral Maxillofac Surg. 2004 Jan;62(1):10-4.Pubmed PMID: 14699542.

[18]. Al-Delayme RM. The effect of cigarette smoking on the severity of pain, swelling and trismus after the surgical extraction of impacted mandibular third molar. J Clin Exp Dent. 2013 Jul 1;5(3):e117-21.Pubmed PMID: 24455065.

[19]. Meechan JG, Macgregor ID, Rogers SN, Hobson RS, Bate JP, Dennison M. The effect of smoking on immediate post-extraction socket filling with blood and on the incidence of painful socket. Br J Oral Maxillofac Surg. 1988 Oct;26(5):402-9.Pubmed PMID: 3263883.
[20]. AlHindi M. Dry socket following teeth extraction: Effect of excessive socket saline irrigation. J Oral Health Dent Sci. 2017 Oct 19;1(1):2-5.

[21]. Kumar MDA, Gheena S. Incidence of dry socket after third molar extraction. Res J Pharm Biol Chem Sci. 2015;7(7):451.

[22]. Saldanha JB, Casati MZ, Neto FH, Sallum EA, Nociti FH. Smoking may affect the alveolar process dimensions and radiographic bone density in maxillary extraction sites: a prospective study in humans. J Oral Maxillofac Surg. 2006 Sep;64(9):1359-65.Pubmed PMID: 16916669.

[23]. Johnson GK, Slach NA. Impact of tobacco use on periodontal status. J Dent Educ. 2001 Apr;65(4):313-21.

[24]. Jesudasan JS, Wahab PU, Sekhar MR. Effectiveness of $0.2 \%$ chlorhexidine gel and a eugenol-based paste on postoperative alveolar osteitis in patients having third molars extracted: a randomised controlled clinical trial. $\mathrm{Br}$ J Oral Maxillofac Surg. 2015 Nov;53(9):826-30.Pubmed PMID: 26188932.

[25]. Patil SB, Durairaj D, Suresh Kumar G, Karthikeyan D, Pradeep D. Comparison of Extended Nasolabial Flap Versus Buccal Fat Pad Graft in the Surgical Management of Oral Submucous Fibrosis: A Prospective Pilot Study. J Maxillofac Oral Surg. 2017 Sep;16(3):312-321.Pubmed PMID: 28717289.

[26]. Kumar S, Snena S. Knowledge and awareness regarding antibiotic prophylaxis for infective endocarditis among undergraduate dental students. Asian J Pharm Clin Res. 2016;9:154-9.

[27]. Ahamed A, Kumar MPS. Knowledge, attitude and perceived confidence in handling medical emergencies among dental students. Res J Pharm Biol Chem Sci. 2016;8(7):645

[28]. Larrazábal C, García B, Peñarrocha M, Peñarrocha M. Influence of oral hygiene and smoking on pain and swelling after surgical extraction of impacted mandibular third molars. J Oral Maxillofac Surg. 2010 Jan;68(1):43-6.Pubmed PMID: 20006153.

[29]. Zajak J, Kralíkova E, Pafko P, Bortlicek Z. [Smoking and postoperative complications]. Rozhl Chir. 2013 Sep;92(9):501-5.

[30]. Balaji SM. Tobacco smoking and surgical healing of oral tissues: a review. Indian J Dent Res. 2008 Oct-Dec;19(4):344-8.Pubmed PMID: 19075440

[31]. Giorgetti AP, César Neto JB, Casati MZ, Sallum EA, Nociti Júnior FH. Cigarette smoke inhalation influences bone healing of post-extraction tooth socket: a histometric study in rats. Braz Dent J. 2012;23(3):228-34.Pubmed PMID: 22814691.

[32]. Sweet JB, Butler DP. Increased incidence of postoperative localized osteitis in mandibular third molar surgery associated with patients using oral contraceptives. Am J Obstet Gynecol. 1977 Mar 1;127(5):518-9.Pubmed PMID: 836651 .

[33]. Heng CK, Badner VM, Clemens DL, Mercer LT, Mercer DW. The relationship of cigarette smoking to postoperative complications from dental extractions among female inmates. Oral Surg Oral Med Oral Pathol Oral Radiol Endod. 2007 Dec;104(6):757-62.Pubmed PMID: 17764988.

Special Issue on
"Oral Microbiology and Dental Infection"
Theme Edited by:
Harry D. Koumoullis,
University of Aberdeen Medical School \& Health Sci-
ences, UK
E-mail: f_hattab@hotmail.com

